\title{
Business Ethics and their Impact on Activating Accountability of Responsibility in light of Contemporary Global Challenges
}

\author{
Rawaz Ahmed Darwish \\ Erbil Polytechnic University - Technical College \\ Iraq
}

\begin{abstract}
A study of business ethics and its impact on accountability in the light of contemporary global challenges Accountability emerged as a subsystem of the administrative accounting system to provide accounting information in the form of performance reports that monitor the work of departmental and departmental officials and assess their performance within the framework of the responsibility given to them by the senior management. In this context, we will focus on the above by linking the work ethic and the supposed accountant to force them to explain, teach and encourage these ethical principles because of their effects in raising the quality of accounting information and thus influencing the administrative decisions taken.

The problem of research is not enough attention to work ethic and is supposed to be an accountant and an obligation to do so and to clarify and raise awareness and encourage this ethics, because of its implications in raising the quality of accounting information and thus affect the administrative decisions taken.

The research requires that the promotion of business ethics through the method of reward and punishment and through awareness and clarification and the establishment of the rules of these principles with the accountant is working to activate the role of accounting in monitoring and evaluation.

At the end of the research, one of the most important conclusions is that liability accounting is an effective control tool that can be used to monitor and evaluate performance. One of the most important recommendations recommends that accountability should be used in units applied to the decentralized system for the purpose of evaluating and supervising the performance of departmental managers.
\end{abstract}




\section{Introduction}

Accountability of accountability has emerged as a subsystem of the management accounting system to provide accounting information in the form of performance reports that monitor the work of officials in departments and departments and evaluate their performance within the framework of the responsibility assigned to them and stemming from the powers granted by the senior management.

Since the powers generate responsibility, the monitoring and performance evaluation will be limited within the limits of the mandates given within the decisions that can be taken at each level of management and since the preparation of performance reports by a human and intended to measure the performance of another Annan so there are several elements and behaviors control how these reports These behaviors include the work ethic that governs the work of the accountant in the preparation of performance, which defines the two prohibitions are the ethics of professional work that govern the principles and rules of accounting and legal as objectivity, reliability, impartiality and the appropriate timing must be available in accounting information and Earmuffs selfbusiness control principles and belief of religious and customary stems from a personal related to the environment and society Taatotr within the justice and a sense of responsibility, faith and sincerity and taking into account other concepts of factors, but this does not prevent the existence of a conflict between professional and selfwork ethic, there are legal acts, but not ethical

There are ethical but illegal acts. However, business ethics within a personal and professional framework of the MOU are important and necessary as a motivation to achieve the goal of accountability by raising the quality, reliability, and fairness of the accounting information contained in the performance reports.

\section{Significant of Study}

The importance of research stems from the great role played by ethics in general and business ethics in particular in supporting the efficiency and effectiveness of the accounting work in the business, especially the performance reports against which the performance of managers in departments and branches in the establishment is measured.

\section{Research problem:}

The lack of sufficient attention to the ethics of the business and supposed to be the accountant and the obligation to do so and to clarify and sensitize and encourage this ethics, because of their implications in raising the quality of accounting information and thus impact on the administrative decisions taken.

\section{Search Hypothesis:}

Encouraging the ethics of business through the method of reward and punishment and through awareness, clarification, and the establishment of rules for these principles with the accountant is working to activate the role of accounting accountability in monitoring and evaluation.

Research Objectives

The research aims to show the clarification of business ethics in general and the role that these ethics play in activating accounting if they are represented in the administrative accountant prepared for the performance reports. 
Research Methodology:

The researcher relied on the descriptive approach in the formulation of the research by reference to the scientific books related to the subject of the research.

\section{Research Plan}

In order to achieve the goal of research and its areas, the research was divided into three sections:

1- Accountability of the liability and the specific behavioral aspects thereof.

2- Business ethics and responsibilities for the accountant.

3- Activate the role of accountability of responsibility through business ethics.

1- Accountability of the liability and the specific behavioral aspects:

The concept of liability accounting

With the breadth and size of the projects, the chair of the board of directors of the establishment or its general manager cannot take all the administrative decisions necessary for their projects. Therefore, a degree of decentralization should be made by delegating the authorities to the lower administrative levels and determining their responsibilities. In this case, each manager is responsible for the performance of his department; At the same time he has the freedom to make administrative decisions concerning the name or administration responsible for them (Abdel Rahim et al., 1990: 599). Hence, accounting of responsibility as a method aimed at monitoring and evaluating performance by determining the responsibility of the two worlds in the economic unit at their different levels of management from the actual performance and the consequent preferred and unpopular results compared to the planned performance. (Ranger, 2004: 423).

There are several definitions of liability accounting. It has been defined as based on the basic premise that individuals must be prepared to be accountable for their performance as well as the performance of their subordinates. Hence, accountability of liability requires that standards and functions be linked to responsibilities so that accounting reports and performance evaluations can be performed Hadi (Heitger et Mauloch, 2000: 456). It is defined as the system that recognizes the different decisionmaking centers, which achieves linking the accounting control with the organizational structure and assesses the performance of those responsible for these centers, which are called responsibility centers based on the factors under their control. (Abdellatif, 2004: 358). It is also known that administrative processes are subject to the provision of information that helps to monitor operations and evaluate performance. (Hussein, 2000: 132).

From previous definitions, liability accounting can be defined as a system that provides accounting information for the performance of departmental managers through performance reports based on comparing the actual performance with the plan to reach deviations (negative or positive) and linking them with the person in charge of the entity.

\section{Objectives of accountability:}

Controlling the elements of costs, revenues, assets, or liabilities is a traditional concept of control because the main reason for achieving the desired objectives of these elements is the human element, which is the main engine of those elements. 
Therefore, it is logical to take responsibility for controlling the insult in the occurrence of the thing and not the end result itself . (Basile, 2001: 318). The objectives of liability accounting are: (Saleh, 2000: 451-452).

1. Linking elements of the activity to those responsible on the basis of the concept of scalability.

2. Assistance in the planning, organization and control process.

3. Provide a plan of incentives on an objective basis through which to prove each of the improved performance and achieve the rates specified within the scope of responsibility and punishment or guidance to anyone who did not achieve what is set for him.

4.

\section{Components of liability accounting:}

A)In order to apply the liability accounting method, the following is required (AlHares, 2004: 425).

Determine the scope of authority and responsibility in a clear and specific manner.

B) Defining performance rates in advance.

C) Training managers to use the results of reports.

D) Reports must be in the hands of managers in a timely manner.

E) Fit the contents of this style reports with authority and levels of managers.

F) Reports should include aspects that managers should be aware of it.

Based on the above, the method of accountability of liability includes the introduction of accounting, administrative, organizational and behavioral common and the success of this is required to integrate these elements into one application. (Hashim, 1988: 230) depends on three main components:

1. Clearly define responsibility centers:

One of the basic components of accountability is the division of the enterprise into centers of responsibility, each of which is under the responsibility of a responsible person. Ie, the division of the economic unit into centers of responsibility. The status of responsibility means any organizational unit headed by a person responsible for the activity of that unit (para. 2000: 452). Responsibility centers are divided into three types:

Cost centers:

The cost center is an activity department whose manager is primarily responsible for the costs involved, and the purpose of which is to reduce the cost to the lowest possible level. The income and capital invested are not within his responsibility and accountability (eg, Hanan, 1997: 418) Costs that may be affected by its decisions.

Profit Centers:

Profitability Center is an organizational unit in which the responsibility of the officer is extended to cover both revenue and costs. Thus, profitability status can be seen as an economic unit whose results can be measured. (Zamil, 2000: 515). Thus, net profit or loss can be an indicator of judging the efficiency and effectiveness of this performance by virtue of the existence of the authority to maximize profits. Therefore, profit centers are more comprehensive than the cost centers. Investment Centers: 
The Investment Center is an activity department whose manager is primarily responsible for its revenues and costs, as well as taking into account the resources and assets invested in the center of responsibility. The Investment Center is therefore developing profitability. (Hawala and Hanan, 1997: 420). It is noted here that the Investment Center is broader with the profitability center, to add the invested capital as an additional element to be followed to evaluate the performance of the department so the performance evaluation is more accurate in the investment centers.

2. Defining performance standards

The liability accounting system in the performance evaluation relies on responsibility centers to compare the actual performance with a certain standard for both costs and revenues. Performance standards are considered as measurement tools with specific specifications that do not depart from being indicators to judge the efficiency and effectiveness of the results of the activity being carried out (Saleh, 2000: 453) When determining standards, consideration should be given to the following: (Ranger, 2004: 428-429).

A) The selection of criteria that reflect the most accurate expression of the level of performance of the centers of responsibility!

B) Taking into account the realism when choosing the level at which the standard is to be established.

C) The standards shall be accurate and understandable by all officials.

D) The standards shall be inclusive of the different aspects of performance.

E) The standard should clarify what should be objectively performed, noting that the performance indicators in the previous three positions are: (Kahala and Hanan, 1997: 422).

Cost center: The cost index shall be based on the costs subject to the control of the Director of the Center and affected by his decisions.

Profitability Center: The net profit index $(*)$ is based.

$\mathrm{C}$ - Investment Center: The index of the rate of return on investment that results from the value of profit on the capital invested, and the remaining profit index resulting from the reduction of the cost of capital invested (capital invested $\times$ desired return) of profit.

3. Design of the accounting system for the centers of responsibility:

When accounting for responsibility, the responsibility centers in the economic unit become the starting point in the design of the accounting system and the compilation of accounting data and the accounts are tabulated and codified on this basis (Al-Hares, 2004: 429).

\section{Performance reports}

The performance reports provided by the liability accounting system represent the means of communication between the different centers of responsibility in the context of the organizational structure of the economic unit and are mainly used for internal administrative purposes in order to assess the performance of responsibility for the various responsibility centers, whether cost, profit or investment. These reports are 
prepared and submitted to administrative levels. The highest through the liability reporting system. (Abdel Latif, 2004: 359).

Performance reports include summaries of departmental results and analysis of trends that assist management levels in monitoring and performance evaluation. As well as containing the measurement or comparison of individual elements under the control of responsible persons. (Saleh, 2000: 454) It should be noted that there is no optimal set of reports suitable for all enterprises, there are reports suitable to measure the performance in a particular facility may not be useful in measuring performance in another facility and there is a set of principles must be considered in the preparation Reports such as ease, clarity and timeliness, consistency in the format of the report, appropriate reports for both the administrative level provided to him and the scope of responsibility as well as the exclusion of unaudited costs from performance reports.

\section{Behavioral aspects and accountability:}

The Performance Appraisal process has behavioral aspects because performance measurement is directly related to the achievement of individuals within projects, and the desired feedback responses are covered in the preparation of reports. Individuals understand in advance how to calculate performance measures and how to allocate responsibility for costs. (Arbeed, 2003: 190) Since man is the essence of accountability, he can detect deviation, identify the person responsible for it, and determine the causes of it. Therefore, liability accounting is more concerned with the individual who causes the deviation than with the element in which the deviation occurred. (Al-Hares, 2004: 424). This clearly illustrates the importance of the behavioral aspect of monitoring and performance evaluation, which is reflected in the actions of the workers in the facility, such as the interest of technicians in the engineering and technical factors in the preparation of standards, ignoring the behavioral aspects leads to a large gap between these standards Implementation as a humanitarian and behavioral style. (Zamil, 2000: 523). Therefore, the degree of effectiveness of accounting for responsibility in the control and evaluation of performance, especially in the preparation of the evaluation criteria is significantly affected by the human behavior of the employees applied to these standards and may be equivalent to the technical aspect of this standard factor may lose interest in work or loss of self-confidence due to non-pressure The system of participation in the development of the standard or consultation will eliminate most of the mentioned problems as well as incentives and moral and material rewards to develop the behavioral orientation of individuals For established to make greater effort standard and therefore sense of responsibility towards this standard and accepted evaluation of performance and accountability of accounting for its implementation .Business ethics and responsibilities for the accountant

\section{The concept of business ethics}

The human behavior of the Muslim is governed by Islamic moral values which are based on the responsibility before God Almighty, which necessitates observing the human values associated with this behavior such as conviction, honesty, honesty, loyalty and justice. Ethics is a state of mind, not a set of rules. Morality is defined as principles related to characteristics such as honesty, integrity, reliability, 
responsibility, and other aspects of good conduct versus misconduct. (Hammad, 2004, 162) Ethics is also defined as standards of behavior and behavior that we expect people to follow. Personal ethics relate to the individual's daily activities. (AlSabbagh, 2002: 204) Integrity and moral values are the product of moral and behavioral standards of unity and how they can be communicated and committed in practice and include the administration's actions to remove or reduce incentives and inducements that induce individuals to commit dishonest, illegal or immoral acts (Lutfi, 2005: 5014). Therefore, business ethics are related to the behavior of individuals in their various practical activities. This includes the way they deal with their colleagues, customers and anyone else who deals with economic unity, and some find it difficult to determine where personal ethics and business ethics begin. $T$ covers business ethics, it is important to differentiate between ethical behavior and legal behavior, morality is the expected behavior with individuals, either with the laws and questions acts required, there may be a legal act, but it is immoral, or unethical, but illegal. (Al-Sabbagh, 2002: 204).

Moral behavior includes the choice of behaviors that are sound, appropriate, and fair, and may be sound or wrong, and may be appropriate or inappropriate, and decisions that may be taken may be fair or unfair. Although individuals are always different in their views on the meaning of ethical values, there is a general principle that is the basis of all moral systems: the belief that every member of any group bears some responsibility for the welfare and well-being of other members of the group, since the individual's desire to sacrifice self-interest For the well-being of the group, it serves as the heart of moral conduct. (Abu Zaid and Mari, 2004: 73), then the ethics of business are limited within the framework of the behavior of individuals within the economic unit or in any other activity is to deal with others from colleagues or customers or management.

\section{Components of the ethical behavior of the accountant:}

The components of the ethical behavior of the accountant can be presented through the following: (Judge and Dodh, 1999: 43-45).

.1The ethical problem: one that arises when one has to choose between several alternatives. The correct decision is not clear at all. The moral problem can be put as one of the alternative options that affect others, so when confronted with the problem, one must return to the ethical principles that he believes in it.

.2Ethical principles: in practice, there are two types of ethical principles that represent a theoretical background for each behavior:

A. The first type: mandatory principles that lead the decision maker to work according to the requirements of the rules of professional conduct without balancing the good and evil as ethics according to this concept are the rules or not to take them.

$\mathrm{B}$ - The second type: are utilitarian principles The basic criterion in these principles is the results of the balance between good and evil resulting from each decision.

3 - The results of the moral decision: The decision that leads to the greatest good is the best decision and that any moral rule should be beneficial to people, either if this rule is harmful may not be applied to them, knowing that the moral decision goes through several steps: 
Examine and clarify alternative works and identify the appropriate possibilities to work in these circumstances and search for all available alternative works.

Focus on thinking about the results of each action or every decision that can be made by predicting a future situation.

C) To be able to assume the decision-making status of the decision-maker.

D) relate to the views of those presumed affected by the decision taken!

Principles of business ethics for the accountant

There are some basic ethical values that represent a series of principles and define, in general terms, what is right or wrong, in general terms. These are the following general principles: Abu Zaid and Mar'i (2004: 73).

These principles represent a general morality, as for the business ethics of the accountant are: (Juma, 2000: 384-385).

Trust: An accountant should be reliable in the performance of his duties and professional and professional services and require confidence that his behavior is characterized by integrity, honesty, integrity, integrity and maintain the confidentiality of information in his institution.

1- Legitimacy: The accountant must prove the legitimacy of everything related to his work and the performance of his duties and professional and professional services in the light of the provisions and principles of Islamic legitimacy.

2- Professional competence and mastery of work: The accountant should be worthy of all his tasks and perform his duties and professional and professional services in the fullest of care and perfection and spare no effort in the fulfillment of his responsibilities towards his Lord and his community and profession and his bosses and his client and himself.

3- Objectivity: The accountant should be fair neutral and neutral impartiality and avoid putting himself in a position of conflict with his interests with the interests of those who serve them.

4- Security behavior: The behavior and behavior of the accountant must be consistent with the values of faith derived from the provisions and principles of Islamic law.

5- Professional behavior and technical standards: The accountant must take into account in his actions the rules of professional conduct and abide by professional standards in the performance of his professional duties.

It is noted that there are common principles between the general principles of ethics and the ethics of the work of the accountant such as trust, objectivity, ethics, workmanship and other principles found in the general principles only as a sense of responsibility and others found in the principles of accounting ethics only and which are based on professional foundations and technical standards.

Standards of the ethical conduct of the accountant and his responsibilities when accounting information is used for auditing and performance evaluation purposes, the accountant may be under pressure from the management to show the results without their truth. The way the accountant deals with these pressures depends on his beliefs and moral makeup, as well as on the extent to which he is affected by the reactions prevailing in the economic unit. The accountant may face the behavior of some employees or supervisors legally acceptable but morally unacceptable in this case may feel acceptable, if the individual is not supported by his beliefs and moral values, it may be difficult to cope with such pressures. (Nur and others, 2005: 25), so it is the 
responsibility of the accountant moral responsibility towards himself and those around him in the economic unity in the need to observe the ethics of the profession on the one hand and self-ethics on the other hand and cohesion consists of the ethics of the work of the accountant and can be represented by the criterion of this ethical behavior, Abu Zaid and Mar'i, 2004: 74-75).

1- Capacity: The accountant has the following responsibilities:

- Maintain an appropriate level of professional competence by continuously developing their knowledge and skills.

- Perform professional duties in accordance with appropriate laws, regulations and technical standards.

- Prepare full reports and recommendations after conducting a reliable analysis of reliable information

2- $\quad$ Confidentiality: The accountants bear the following responsibilities:

- Refrain from disclosing any information obtained through work unless there is a legal obligation to disclose such information.

- Inform the assistants in respect of the confidentiality of the information they obtain in case of authorization and follow up their activities to ensure confidentiality.

- Refrain from using the confidential information available to them through work in order to obtain an unethical or illegal advantage.

3- Integrity: The accountant bears the following responsibilities:

- Avoid situations of conflict of actual or apparent interests and advise all parties on any possible conflict.

- Refrain from engaging in any form that may limit their decisions to carry out their duties in a moral framework.

- Refusing a gift, favor, or courtesy that would affect their behavior.

- To refrain from direct and indirect negative influence on the achievement of the legal and ethical objectives of the enterprise.

- Deliver the appropriate information.

In addition - Refrain from engaging in any activity that would diminish the profession.

Objectivity: The accountant must fulfill the following responsibilities:

- $\quad$ Communicate information fairly and objectively.

- The full disclosure of all appropriate information that can reasonably be expected to affect the user's understanding of the reports, comments or recommendations presented.

4- Activate the role of accountability of responsibility through business ethics:

The focus of work in accountability of responsibility is the individual who participates in the development of standards and against it evaluates the performance of the other individual in the economic unit and prepare reports to the higher management so that the ethics of accounting work largely controls the outputs of this system of accounting 
information can be classified business ethics of the accountant and Controls the effectiveness of the output of the liability accounting system in two groups:

\section{1- Professional Business Ethics:}

These ethics are the degree of confidence in the accounting information produced, including neutrality and non-discrimination, against the conflicting interests of those who use such information and the truth of information, that is to say, the content that aims to represent it honestly and objectively in the imposed information and the ability, professional, technical and scientific expertise to fulfill the work entrusted to him, ie, a commitment of higher administrative and technical bodies. Therefore, this ethics has to be characterized as compulsory in practice and representation based on a rule of law that punishes those who violate these characteristics, rules and principles that must be taken into account Prepare performance reports.

\section{2- Self-service ethics:}

This ethics is related to a relative concept within man, which is the belief, which gives rise to a set of mental principles such as discipline that is to follow ethical behavior, correctness, and integrity, ie, avoiding behaviors that generate pressures that affect his actions and integrity and maintain promise and transparency. The work that is done and the preservation of the confidentiality of information within the unit and justice and these moral principles strengthen or weaken within the accountant according to the degree of faith contained in each of these principles and the basis of this faith is a religious or customary or social challenge In the environment in which the accountant lives, the ethics of professional and self-employment can be represented as follows:

Activate the quality of performance reports:

Accounting information is the focus of what is included in the performance reports. Therefore, in order to activate the role of performance reports in achieving the objectives set for it and to raise the quality of the accounting information it contains and thus to achieve the highest adequacy of the users of the reports and the beneficiaries of that information and to support the quality of the decision taken based on these reports, Information and control of the conduct and results of business ethics previously mentioned. The ethics of business has the great effect of raising, consolidating, reducing or weakening the quality of performance reports. In order to activate the quality of performance reports, it is up to the administration in the economic unit to take the following steps:

1- Clarifying the concept of business ethics within the unit.

2- To encourage accountants to represent this ethics and support with incentives and rewards material and moral.

3- Using the method of reward and punishment when discovering ethical attitudes and how it was treated.

4- Develop a sense of responsibility within the accountant prepared to report performance by strengthening the human feeling within the unit based on justice and integrity in assessing the performance of others.

5- Develop a legal, ethical, and professional formula that ensures that the ethics of self-employment are contained. 
Conclusions and recommendations:

Conclusions

1. Liability accounting is an effective control tool that can be used in monitoring and evaluating performance.

2. The ethics of business is the behavior of individuals and their dealings with others and the extent of adoption of this behavior on ethical principles.

3. The business ethic of the accountant includes two groups: professional and other business ethics.

4. Enhancing the business ethics of the accountant ensures that the role of responsibility accounting in monitoring and performance evaluation is enhanced by supporting the effectiveness of the performance reports by raising the quality of the accounting information contained in those reports.

5. Providing performance reports within the framework of business ethics ensures that a wall is built to protect the accountant from moral problems.

Recommendations:

1- The accountability of responsibility should be used in the units applied to the decentralized system for the purpose of evaluating and supervising the performance of managers in the departments.

2- The importance of the existence of standards and ethical rules within the economic unit to regulate and bind the work of the accountant.

3- $\quad$ The need to use the method of reward and punishment and material and moral incentives to strengthen the business ethics of the accountant in the economic unit.

4- - To provide courses for accounting staff within the economic unit to clarify and encourage the accountant to comply with the principles of business ethics.

5- The accountant should not use performance reports as a means to make mistakes or blame the manager responsible or punishment, but must use these reports to identify the fundamental deviations and study and examine and know the reasons and help the manager to take remedial actions and treatment.

\section{REFERENCES}

1- Ahmed Helmi Gomaa, 2000, (Modern Approach to Auditing), 1, Safa House for Publishing and Distribution, Amman.

2- Ahmed Hussein Ali Hussein, 2000, (Advanced Administrative Accounting), I 1, University House, Alexandria.

3- Ahmed Mohamed Bassiouni Hashim, 1988, (accounting management), Dar books for printing and publishing, Mosul.

4- Ahmed Mohamed Noor, Zeinat Mohamed Moharram and Shehata Shehata, 2005, (Management Accounting in Contemporary Business Environment), University House, Alexandria.

5- Ahmed Mohamed Zamil, 2000, (Accounting Management with applications on the computer), Institute of Public Administration, Riyadh.

6- Ali Abdul Rahim, Yousef Al-Adly and Mohamed Azmah, 1990 (Fundamentals of Administrative Costs and Accounting), I 1, Al-Sallas, Kuwait. 
7- Essam Fahad Al-Arbeed, 2003, (Management Accounting), 1, Dar AlMihajah, Amman.

8- Gabriel Joseph Kahala and Radwan Helwa Hanan, 1997, (Management Accounting), 1, Dar Al Thaqafa Library for Publishing and Distribution, Amman.

9- Hussein Al-Qadi and Hussein Dodah, 1999, (Fundamentals of Auditing under American and International Standards), 1, Al-Warraq Foundation, Amman.

10-Imad Abdul Wahab Al-Sabbagh, 2002, (Information Science), 1, Dar AlThaqafa for Publishing and Distribution, Amman.

11- Kamal Khalifa Abu Zaid and Attia Abdul Hay Marai, 2004, (Principles of Modern Administrative Accounting), University House, Alexandria.

12-Leicester A. Heger and Serge Matulich, 2000, (Management Accounting), translated by Ahmed Hamed Hajjaj, Dar Al-Marikh for Publishing, Riyadh.

13- Makram Abdel-Masih Basili, 2001, (Administrative Accounting), I 3, Modern Library, Alexandria.

14- Naser Noureddine Abdel Latif, 2004 (Modern Trends in Management Accounting and Information Technology), University House, Alexandria.

15-Osama Al-Hares, 2004, (Accounting Management), 1, Dar Al-Hamed Publishing and Distribution, Amman.

16- Samer Qanatqji, 2004, Islamic Accounting Jurisprudence, 1, Al-Resalah Foundation, Beirut.

17- Samir Abu Al-Fotouh Saleh, 2000, (Strategic Management Accounting), Modern Books, Alexandria.

18-Secretary of Mr. Ahmed Lotfi, 2005, (Review and audit of information systems), University House, Alexandria.

19- Tarek Abdel-Al Hammad, 2004 (Encyclopedia of Auditing Standards), Part I, University House, Alexandria. 